Physics International 3 (1): 9-21, 2012

ISSN 1948-9803

(C) 2012 Science Publications

\title{
Superiority of Prostration as a Protection from Lightning Strike
}

\author{
Miah Muhammad Adel \\ Department of Chemistry and Physics, \\ Interdisciplinary Sciences Research Center, \\ University of Arkansas at Pine Bluff Pine Bluff, AR 71601, US
}

\begin{abstract}
Problem statement: Because of the significant fatalities due to lightning strikes in open fields, exploration has been made to find the human body's most comfortable posture having the lowest length, width and height and the least ground touch in any terrain indoor and outdoor for the safest shelter from lightning strikes that neutralize an enormous amount of positive and negative charges. Approach: Risks of direct lightning strike and of side flash and ground current due to a lightning hit at a nearby place have been discussed along with an estimation of interlimb current for standing, sitting, lying flat and prostrated positions using the fundamental laws of electricity in physics. Results: It is found that prostration in which the body is comfortably squeezed within a length of one meter with the forehead-nose tip, the palms, the knees and the toes grounded, making a maximum body height about $35 \mathrm{~cm}$, offers the least chance of a lightning strike, side flash hit and interlimb current flows, concluding the best shelter against lighting hit. Conclusion/Recommendation: Prostration is superior to all other postures of sitting and lying to lower our body weight in order to avoid dangers of lightning. During lightning, outdoor people who are not in closed safe transportations, or not in otherwise better shelters are recommended to use this posture of the body as a safe protection from lightning strikes. Considering the fatalities caused by lightning, families and communities should hold lighting drills before the advent of the lightning season.
\end{abstract}

Key words: Prostration, lightning, potential difference, induced charge, ground resistivity, human body resistance, current

\section{INTRODUCTION}

Lightning safety is a global issue. There are many countries where lightning consequences are more often than in the USA. Lightning causes deaths and injuries to human and livestocks and damages property. General public should have the knowledge of protection from a lightning - strike so that life and property losses are kept to a minimum. The earth receives about 100 lightnings every second and every year lightning kills more people than tornadoes and hurricanes and most of these deaths take place in open fields near or under trees or around water.

Holle (NLSI, 2012) reported about 24,000 lightningstruck deaths and about 240,000 lightning-struck injuries globally every year (Al-Abdulaziz et al., 2006; Coleman, 1993; Demirkol et al., 1999; Djalel et al., 2007; Halasa et al., 2007; Khan et al., 2002; Koopman and Wilkerson, 1971; Meredith et al., 2010a; 2010b; Odeh, 2009; Petersen et al., 2008; Rambo et al., 1999; Saum and Koopman, 1972; Stolzenburg and Marshall, 2008). Roach 2004 reports for National Geographic News (Dell'Amore, 2010) of more lightning victims than snow storms, hurricanes and tornadoes. Only floods can supersede this figure for lightning.
Also, Roach 2005 reports for National Geographic from a meeting organized by NOAA and its partners (Dell'Amore, 2010) of 3,696 deaths in the U.S. between 1959 and 2003. Lightning-related injuries range from severe burns and permanent brain damage to memory loss and personality change. Deaths occur to about $10 \%$ lightning-stroke victims and about $70 \%$ becomes prolonged sufferers. Lightning is found in thunderstorms, volcanic eruptions, extremely intense forest fires, surface nuclear detonations, heavy snowstorms and in large hurricanes. In the USA, the probability of being a lightning victim is one in 700,000 and that of being struck is one in 3,000. The website http://articles.cnn.com/keyword/lightning-strikes keeps the latest account including that of 2011 on lightning strikes in the USA and some foreign countries.

Lightning is a neutralization of electric charge in which positive and negative charges from separate locations combine. This neutralization can happen between two parts of the same cloud, two different clouds and cloud and ground. Lighting is a momentary event whose details are not commonly observed. It occurs in cumulonimbus clouds. The condition for lightning is the creation of positive and negative 
charges separated in two parts of a cumulonimbus cloud. It is believed that the charges develop through friction. The layer of positive charges resides above the layer of negative charges in the cloud.

A lightning flash consists of a few strokes that take place back to back within a few ten Milli sec's. There may be three or four strokes or even 26 strokes in just two sec (Jewett and Serway, 2007). The interval between strokes is not detectable because of their quick succession.

The strokes are triggered when there is electrical breakdown. At room temperature, the electrical breakdown voltage of air is 3 million volts per meter of air (Giordano, 2009). The electrical breakdown creates piller like distributions of negative charges. This is called stepped leader and approaches the ground in steps with a speed of more than a million meters per second carrying a current of 200-300 Amperes. The electrons that make up this current can make a step forward if the surrounding air has sufficient number of ions and electrons. The radius of its path is 3-4 $\mathrm{m}$. As the leader approaches the ground, it breaks down the electrical resistance of the air surrounding any sharp pointed object which loses electron because of the repulsive effect of the electrons with the leader and becomes positively charged. The breakdown of electric resistance causes a stream of positive charges upward triggering the return stroke. At a height of 20-110 meters above the ground the upward moving stream of positive charges and the downward moving negative charges neutralize creating a short circuit between the ground and clouds.

Electrons rain down from the negatively charged clouds. This enormous amount of falling electrons (about 100 million trillion) carrying about 25 coulomb of electric charge creates 50,000 amperes of current.

The conductivity of the current carrying path lasts for a few thousandths of a second after the return stroke. Remaining charges made in the clouds follow the previously established path and creates another new stroke and one more bright lightning flash is observed.

This article shows that of all comfortable body postures in all terrains on land in the open field, prostration is the best one to get protection from lightning.

Human tolerance limits and body resistance: Salt water being a fairly good conductor, human bodies are conductors because of having a large quantity of it. The tolerance limit for direct current for a $70-\mathrm{kg}$ person is 75 milliamperes. For a current within the tolerance limit, it is possible to release the hands from the source of current although the joint muscles get squeezed. Also, the tolerance limit depends on the mass of the muscles. A current of 62 milliamperes is painful for males and 41 milliamperes for females. However, the physical control over voluntary muscles is not lost.

The electrical resistance varies from person to person depending on the body chemistry. Also, in the same individual, different limbs have different electric resistances. A wet body has less resistance than a dry body. In the wet and dry body the resistance from one hand to the other has been measured to be within 17,000 to $1,000,000$ ohms.

Halliday et al. (2008) mention a resistance of 4,000 ohms between the two feet. Giordano (2009) mentions about 1500 ohms between the two hands for a dry body and 500 ohms for a wet body. Internal body has a much smaller resistance-about $85 \mathrm{ohms}$ to 575 ohms. Depending on the skin condition the skin resistance can vary in the range of 1,000 -100,000 ohms. Skin being the outer cover, its resistance has to be counted twice-once to get in through the skin and once to get out through the skin-to find out the total resistance. For the purpose of illustration, we take the resistance between the toe and the knee to be half of that between two extreme ends i. e. 7,500 ohms. From knee to palm, too, we will take the same resistance.

Soil resistivity: The earth behaves like a huge conductor because it has water, moist soil and a variety of ions. The resistivity of the ground depends on the type of soil. Loam soil has 25 ohmmeter, alluvium has 35 ohms. Meter, and sandy soil has 300 ohms. meter. Wet soil has lower resistivity than dry soil (Hyndman and Hyndman, 2010). We assume that alluvium is the predominant variety.

How lightning hurts subjects: Lightning is very dangerous. If it hits directly a person or an object held by the person, the resulting current through his/her body can cause death. If it befalls nearby the person, side flashes can travel around and reach the person. Those floating whitish fire patches can burn nearby persons if no safe refuge is taken. Over water bodies, these charges can travel a long distance. The most common injuries from lightning occurs from this way. And it happens due to standing near any tall and grounded objects like a tree, light pole, etc.

Also, charge can travel through the electrically conducting ground to the person. What else more can happen is that due to the induction effect of the overhead negatively charged clouds, stream of positive charges can flow upward through the body. It may be estimated that a microcoulomb charge will be induced in the person's body. What it means is a few trillion electrons may leave the body resulting it to be 
positively charged. The body's electrical neutrality is broken down. Depending on how fast this occurs, microcoulomb charge flow can create tens of milliamps of current. During a lighting strike, when electrons rain down to the ground forcefully, atmospheric gas atoms become ionized and creates a lot of positive ions and free electrons. These free electrons can enter the body to neutralize the upward moving stream of positive charges. It results in a huge current through the person's body.

Ground current from lightning strike: When a lightning strike the ground, the charge flow hemisphericallly in the ground different types of which will have some varying electrical properties. We denote $i_{\text {ground }}=i_{\text {gr }}$ as the ground current, $\rho_{\text {ground }}=\rho_{\text {gr }}$ as the ground resistivity and $\mathrm{i}_{\text {lightning }}=\mathrm{i}_{\mathrm{li}}$ as the typical lightning current (20,000 Amps).

Let us assume that a charge has covered a hemisphere of radius $r$. Then the ground current density jgr within the ground hemisphere of area $A=2 \pi r^{2}$ through which the charge is advancing on the ground is Eq. 1:

$\mathrm{j}_{\mathrm{gr}}=\mathrm{i}_{\mathrm{li}} / 2 \pi \mathrm{r}^{2}$

The fundamental equations of electricity show the relation involving the ground resistivity $\rho_{\mathrm{gr}}$, the ground electric field $\mathrm{E}_{\mathrm{gr}}$ and the ground charge density $\mathrm{j}_{\mathrm{gr}}$ as Eq. 2:

$\rho_{\mathrm{gr}}=\mathrm{E}_{\mathrm{gr}} / \mathrm{j}_{\mathrm{gr}}$

Whence the ground electric field is Eq. 3:

$\mathrm{E}_{\mathrm{gr}}=\rho_{\mathrm{gr}} \mathrm{i}_{\mathrm{li}} / 2 \pi \mathrm{r}^{2}$

Also, the ground electric field is obtained from the negative gradient of the ground potential difference. We consider two ground hemispherical layers at radius $r$ and $\mathrm{r}+\Delta \mathrm{r}$ away from the center of the hemisphere. The layer $\mathrm{r}$ is at potential $\mathrm{V}$ and $\mathrm{r}+\Delta \mathrm{r}$ at $\mathrm{V}+\Delta \mathrm{V}$ where $\Delta \mathrm{V}$ will be negative because of falling off of the voltage with increasing distance. The potential difference between the layers Eq. 4:

$$
\Delta V=-\int_{r}^{r+\Delta r} E_{g r} d r
$$

Integration yields Eq. 5-6:

$$
\Delta V=-\left(\rho_{\mathrm{gr}} \mathrm{i}_{\mathrm{li}} / 2 \pi\right) \int^{\mathrm{r}+\Delta \mathrm{r}}
$$

$\Delta \mathrm{V}=-\left(\rho_{\mathrm{gr}} \mathrm{i}_{\mathrm{li}} / 2 \pi\right)[\Delta \mathrm{r} /(\mathrm{r}(\mathrm{r}+\Delta \mathrm{r}))]$

The interlimb distances are assumed to be very small compared to the distance to the lightning spot. If a lightning strikes a distance of about $10 \mathrm{~m}$ away from the subject, the maximum interlimb distance becomes a few hundredths of the distance to the lightning spot. We can take this to be the upper limit. On the other extreme, the interlimb distances could be even less than a few hundredths of the distance to the lightning spot if the latter is more than $10 \mathrm{~m} \mathrm{Eq.} \mathrm{7-9:}$

With $\Delta \mathrm{r}<<\mathrm{r}, \Delta \mathrm{V}=-\left(\rho_{\mathrm{gr}} \mathrm{i}_{\mathrm{li}} / 2 \pi\right)\left[\Delta \mathrm{r} / \mathrm{r}^{2}(1+\Delta \mathrm{r} / \mathrm{r})\right]$

$\Delta \mathrm{V}=-\left(\rho_{\mathrm{gr}} \mathrm{i}_{\mathrm{li}} / 2 \pi\right)\left[\left(\Delta \mathrm{r} / \mathrm{r}^{2}\right)(1-\Delta \mathrm{r} / \mathrm{r})\right]$

$\Delta \mathrm{V}=-\left(\rho_{\mathrm{gr}} \mathrm{i}_{\mathrm{li}} / 2 \pi\right)\left[\Delta \mathrm{r} / \mathrm{r}^{2}\right]$

After dropping the squared and higher order terms in $\Delta \mathrm{r}$. Now the current through the body parts = grounded inter-limb potential difference /inter-limb resistance Eq. 10-13:

$\mathrm{i}_{\text {inter-limb }}=\Delta \mathrm{V} /$ inter-limb resistance
$\mathrm{i}_{\text {inter-limb }}=\Delta \mathrm{V} / \mathrm{R}_{\text {inter-limb }}$
$\mathrm{i}_{\text {inter-limb }}=\left(\rho_{\mathrm{gr}} \mathrm{i}_{\mathrm{li}} / 2 \pi\right)\left[\Delta \mathrm{r} / \mathrm{r}^{2}\right] / \mathrm{R}_{\text {inter-limb }}$

$\mathrm{i}_{\text {inter-limb }}=\left[(0.16)\left(\rho_{\mathrm{gr}}\right)\left(\mathrm{i}_{\mathrm{li}}\right)(\right.$ inter - limb distance $\left.)\right] /$

[(subject - lightning distance squared)

$\mathrm{x}($ interlimb resistance $)]$

We substitute $\rho_{\mathrm{gr}}=35 \mathrm{ohm}$.meter, lightning current $\mathrm{i}_{\mathrm{li}}=20,000$ Amps, the maximum interlimb distance $=$ $0.40 \mathrm{~m}$ and interlimb resistance $\mathrm{R}_{\text {inter-limb }}=7,500 \mathrm{ohms}$. Eq. 13 then yields less than 6 amps. meter ${ }^{2}$ without substituting the object-lightning distance squared. For a 62 milliamp tolerance limit, it is found that the person, if in the prostration position, can be safe from as close a lightning hit on the ground as $10 \mathrm{~m}$ away!

Ground current is generated if lightning strikes the ground. Injuries from ground current can be less severe than direct strike or side flash incidents. Wet ground increases the danger from ground current.

\section{MATERIALS AND METHODS}

Methodology: The methodology consists in the estimation of the current through our body and the inter-limb current for common postures of the body, assumed to be a certain distance away from a spot hit 
by lightning. Several physical postures are discussed along with their risks. These include standing, sitting in yoga meditation, knee-folded sitting on toes, kneefolded sitting on feet, lying down on the ground and prostrated. Out of all these postures, prostration has the lowest height and possibly, the length. Background objects taller than the prostration height is likely to be favored in lightning strikes, saving the person in prostration. However, the ground current can reach the person in prostration if a lightning strikes at a nearby spot on the ground. From the lightning-hit position, hemispheres will be drawn with different radii touching the grounded limbs of the subject in prostration. Grounded interlimb distances of the person in prostration will be measured. Equation 13 above will be used to estimate the interlimb current. Adjacent grounded limbs form an electric circuit through the ground. Grounded interlimb distances being very short, tolerable current is expected to pass through them, rendering this position safe from the ground current, too.

Safety inside an automobile: Modern cars do not offer a guaranteed safety because of having many electrical components inside. Also, cars with fabric tops or cars that are made of fiberglass are unsafe. A vehicle offers some protection but not $100 \%$ as some people claim. The reason of safety in many cars lies in the conductivity of a car's metal body which has curvatures, folds, highs and lows, etc. Electric charge accumulates on the top surface of the curved of metal bodies. An accumulation of charge occurs on the bottom side of curved metal surfaces or under the roof. Passengers can touch the ceiling without having any charge flow through their body. During lightning, it is risky to sit on the rooftops of cars, buses, and trains, a common sight in Bangladesh. Also, while inside the car, the windows have to be closed and no metal parts can be touched. Further, the car should be parked by the srteetside and steering wheel, gearshift and radio cannot be touched (Albornoz, 2007).

Standing: Standing is a very risky position under lightning. Most of the lightning-hit deaths occur in this position. We are in the standing posture while we are working outside or walking. At a time, more people are outside on foot in the third world countries which makes more deaths in this posture of the body. In the standing position, all the three ways of lightning hit have some risks but the greatest risk being from a direct hit and induction. During alighting, the taller we stand, the more likely it is to be a source of the positive charge stream as said above. It is not safe either to stand under a tall tree. If lightning strikes the tree, when traveling to the ground, charge can jump to a nearby standing person and travel to ground through his body. In standing, we may take the adult average height is about $1.75 \mathrm{~m}$. The standing position is very stable and comfortable. The interfoot distance $\Delta \mathrm{r}$ between the two feet can be made zero by touching each other. This makes the potential difference between the two feet zero and no current flow through the body from a nearby lightning ground strike. While no ground current flow through the body, there is enormous risk of being hit by lightning because of the height by playing as an object of the positive charge stream. A lightning strike case has been cited in the Note section for a person of height about $2.25 \mathrm{~m}$ including the load of grass he was carrying. So, standing cannot be recommended as a safety against lightning hit.

Sitting: In this position, individuals sit on their buttocks, folded knees offer additional support. The height is reduced to almost half of an average adult height. This height may be surpassing the heights of many objects in the surroundings. It still carries the risk of lightning hit by turning it to be a source of positive charges. The two feet may be at the same potential and there will be a little potential difference between the feet and the buttocks. On each side, tolerable current will flow from each foot through the knee-fold through the thigh and the buttock and the ground. However, this is not a comfortable position as well, particularly, on an uneven ground having chunks of rocks or chunks of hard soils. Also, sitting on a sloping terrain will not be comfortable.

A subject can sit on two toes with knee folding and buttocks not touching the ground. This is an uncomfortable sitting position. A small stick as a support can be used. The height is foot height plus the height of the waist to head. The height from the ground may about a meter. However, people with long necks will have a taller height. The position is very uncomfortable for bulky persons. Terrain characteristics can magnify the discomfort. This uncomfortable position still carries the risk of being a source of positive charges.

A subject can sit about two feet with knees folding and buttocks not touching the ground, too. This position is very uncomfortable for obese persons. For long-necked persons, the height from the ground is about $1 \mathrm{~m}$. On a ramp, none of these sitting postures will be comfortable and stable. Rocky terrain either will not give a better spot for the sitting position.

Lying down: Lying down yields the lowest height from the ground. Lying on the back or on the chest makes the body height equal to the thickness of the body 
measured from the front to the back. Lying on any side makes the body height equal to the body width measured from the right side to the left side. It is thought that there could be a large potential difference between the feet and the head causing a large current to flow. The likely reason for this is that a place found at random at the time of lightning may not be smooth. People working on plowed agricultural lands will have a hard time in lying over rock hard soil lumps before the advent of the monsoon. Also, it will be hard to lie over rocky terrain. Further, our bodies have dips, joints and folds that prevent from uniformly touching the randomness found a spot for lying. So, while the risks of lightning hit are minimized, the risks of ground current flow through the body are increased.

Prostration: Many religions have the custom of making prostration in their religious rituals. And the prostrations are made in front of the statues of their deities or preachers on religious occasions. Muslims, by far, make the highest number of prostrations on a daily basis-at least thirty four prostrations in seventeen units of obligatory prayers. Each unit of optional prayer will further add two back to back prostrations. They prostrate in the direction of their Grand Mosque in Mecca from wherever they are. The prostration performed as a protection from lightning can be in any direction.

Prostration consists in making distributed touch on the ground by our body parts at the same time having the height lowered than the height while sitting on the toes or feet with the neck bent to lower the head. Distributed groundtouch makes the posture very comfortable. In prostration, the heaviest part of the body-the waist to shoulder part is supported by the two knees and the two palms. The head is supported by the nose tip and the forehead. All these limbs touch the ground on small areas. This is the most comfortable posture for people of all sizes, shapes, ages, sexes. Other than touching the forehead and the nose tip on the ground, this posture (crawling) is the first posture we learn in our life in our first mobility before learning how to walk.

In prostration, the height becomes the lowest possible and the inter-limb distances become very short. The lowest possible posture makes the surrounding objects taller than its height ensuring lesser risks of being struck by a lightning. Also, flow of side flashes occurs above this height. At the end of this article, a practical experience has already been mentioned about the travel distance of side flashes over $100 \mathrm{~m}$ over water bodies. Further, the very short inter-limb distances causes zero to very small potential differences between the limbs. Limbs that touch the ground make up a number of closed electric circuits via the ground. The little or no inter-limb potential differences cause little or no current through these limb circuits.

Table 1 mentions the interlimb distances for an adult male in prostration. Smallest interlimb distance can be $0.5 \mathrm{~cm}$ and the highest can be $40 \mathrm{~cm}$ for a very comfortable prostration. The subject can reduce the interlimb distances further by bringing them closer together. It is still more comfortable and safer than any of the other body postures mentioned above.

Prostration is illustrated in Fig. 1 below. In this situation, the highest height one attains is the height of the knee to the waist inclined at an angle of about 45 degrees. People of average size may have the knee-tohip height of about $50 \mathrm{~cm}$. When this is inclined at an angle of $45^{\circ}$, the actual vertical height becomes about $35 \mathrm{~cm}$ using $50 \cos 45^{\circ}$. What touch the ground are the tips of the first two toes, the knees, the palms, the forehead and the tip of the nose. For each foot, the first toe tip touches the ground about 4 square $\mathrm{cm}$ and the second toe tip touches about half of that size.

Table 1: Inter-limb distances

\begin{tabular}{ll}
\hline Body parts & Distances $(\mathrm{cm})$ \\
\hline Left Toe (LT)-Right Toe (RT) & $10-15$ \\
Left Knee (LK)-Right Knee (RK) & $30-40$ \\
Left Palm (LP)-Right Palm (RP) & $30-40$ \\
Left Toe (LT)-Left Knee (LK) & $35-40$ \\
Left Knee (LK)-Left Palm (LP) & $30-35$ \\
Nosetip (NT)-Forehead (FH) & $05-08$ \\
\hline
\end{tabular}

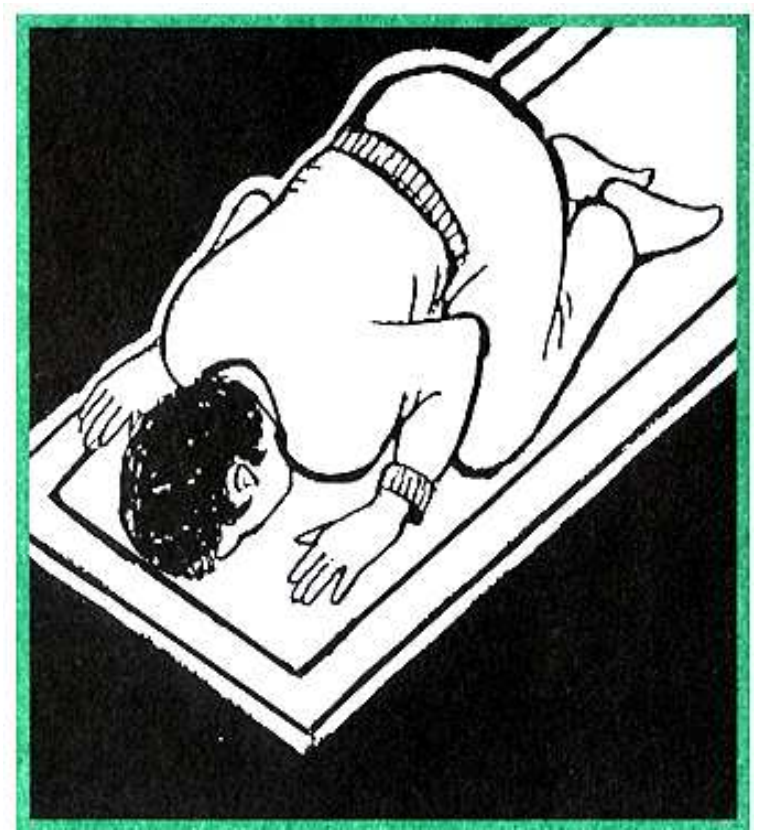

Fig. 1: Illustration of prostration 
Each knee touches about 20 square $\mathrm{cm}$ and each palm touch about 135 square $\mathrm{cm}$ area of the ground. The nose tip touches about 0.25 square $\mathrm{cm}$ and the forehead touches about 2-3 square centimeters. The entire body weight is comfortably and stably supported by these seven limbs counting the nose and the forehead together. One cannot squeeze his/her body any further with any better comfort in any other posture. The distance between the two toes will be in the range of $10-15 \mathrm{~cm}$, between the two knees $30-40 \mathrm{~cm}$ which will also be the distance between the palms. The tip of the nose and forehead will be $5-8 \mathrm{~cm}$ apart from either palm. In the open fields, there will be many objects around-plants, crops, tall grass, trees, with heights higher than the height in prostration. Those objects will be more favored than the person in prostration for a lightning strike. Besides, in prostration our body is squeezed to nearly half its size.

Prostration is the safest posture from not only a lightning strike, but also a protection from dangerous currents from a nearby lightning strike on the ground. The reason is that the current between two points is proportional to the potential difference between the two points. The inter-limb distances that make up the electric circuits via the ground being much smaller than the distance to the lightning-hit spot, there will be little inter-limb voltage differences. If the two points are at the same potential, they have zero potential difference between them and no current will flow. In prostration, either little or no potential difference is achieved between the limbs as illustrated under the discussion below.

Prostration is also the safe refuge from the sideways flash from a lightning strike. Evidence of side flash travel distance up to about $100 \mathrm{~m}$ across water bodies exists (mentioned in the Note section below). These flashes may freely travel longer distances upon water bodies above a height of about $3 \mathrm{~m}$.

\section{RESULTS}

In open space, prostration is the only position that can give the best shelter. It reduces the body height and the body length of the least causing background objects more favorable for lightning strike. Further, prostration brings different limbs-toes, knees, palms, forehead and nose - so close that the potential difference from the ground charge movement becomes zero between the two toes, the two knees and the two palms, the nose tip and the forehead in case of a lightning strike at the back or front of the person in prostration. However, little potential difference develops between the toes and knees and knees and palms, the forehead and the nose tip, causing a tolerable current flow even from a nearby lightning strike on the ground according to the fundamental laws of electricity in physics. For a lightning strike to the left or right side of the prostration position, each side toe, knee and palm become an equipotential with a slightly higher potential on the side nearer to the lightning strike than the other side. The forehead-nose tip falls in between these two potentials. When lightning hits in front-right or front-left positions, the nearest palm has the highest potential and the farthest toe has the lowest potential. The near side knee forms an equipotential across the body with the far side palm and so does the near side toe with the far side knee. For lightning strike at rear-right or rear-left, the nearest toe becomes at the highest potential and the farthest palm at the lowest potential. The near side knee forms an equipotential across the body with the far side toe and the near side palm with the far side knee. Skin of grounded limbs has a higher electrical resistance than the internal organs. The Little voltage difference causes a little current flow through the grounded limbs. The heart, the vital organ of the body remains safe in all cases.

\section{DISCUSSION}

The subject may fall in prostration while lightning may fall behind, in front of, to the right of, to the left of, to the front-right of, to the front-left of, to the rear-right of and to the rear-left of him/her. These are the most likely locations with respect to the subject. However, lightning may be located inbetween those directions, too. For each of those postures, equipotential lines would be drawn through the limbs touching the ground. For each position, distances between different limbs that differ in potential will be measured.

Lightning strike at the back of the subject in prostration: Let us consider the case in which a person is in prostration posture and lightning has struck the ground behind him, say, $100 \mathrm{~m}$ away. From the lightning spot, electric charge flows in a hemispherical volume as shown in Fig. 2a. The person in prostration (Fig. 2b) will have the two toes at the same distance away from the lighting spot. The two knees will be at the same distance away from the spot. The two palms, the forehead and nose will be at the same distance away from the lightning spot. 


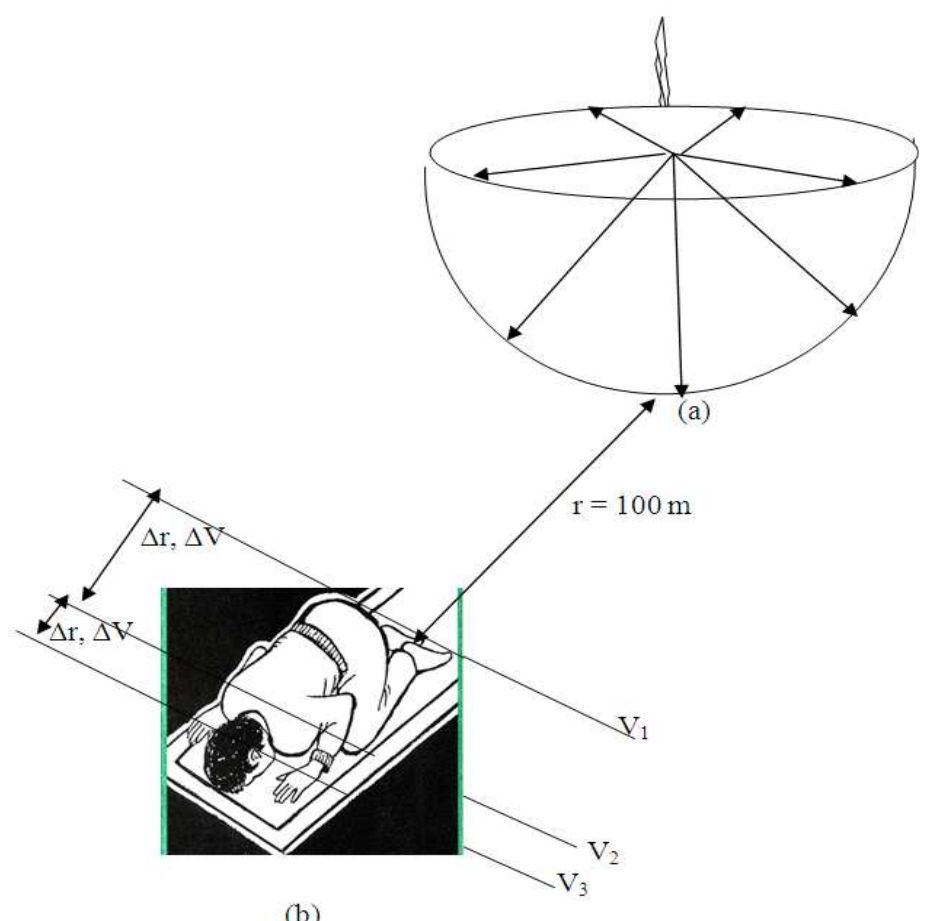

(b)

Fig. 2: (a) Lightning strike and current spread in a hemispherical volume, $r=100 \mathrm{~m}$ is the distance from the lightning-hit spot to the subject's feet, (b) Subject in prostration with the lightning strike behind him

The equidistant limbs will be equipotential. As a result no current flows between the two toes. Also, no current flows between the two knees via the upper halves of the legs and the waist and no current flows between the palms via the hands through the chest. As a result, the heart, the most sensitive and vitally important organ is thereby saved. No current flows from the palms to the head or nose. However, the left toe and the left knee and the right toe and the right knee will be at different distances. So there will be little difference of potential between the toes and the knees. And there will be a little current flow between the toe and the knee of each leg. Similarly, the left knee and the left palm will be at slightly different distances; so also will be the right knee and the right palm. A potential difference will exist and some current will flow from left knee through the left side of the body with the left palm. Also, a current will flow similarly on the right side of the body and that flow will be given by Eq. 13 deduced above.

We take the lightning current to be about 20,000 amps. We can take the toe-knee distance $35-40 \mathrm{~cm}$ and the knee-palm $30-35 \mathrm{~cm}$. Let us take $35 \mathrm{~cm}$ as the average inter-limb distance between toe to knee or knee to palm. Without substituting the object-lightning distance, we find inter-limb current to be about 5/(square of the object lightning distance in meters). We can substitute the square of $100 \mathrm{~m}$ distance which is 10,000 to find that the current between the toe and knee to be about 0.5 milliampere. Because of the higher (at least double) resistance between the knee and the palm, the current will be about 0.25 milliamperes. The person in prostration may feel tingling effect only. It is obvious from the current formula (Eq. 13) that the current flow between the two limbs can be made much smaller by shortening the relative distances between the two limbs. And it is only in prostration that it can be achieved. Thus, it is found that the little current flows through the peripheral parts of the body and not through the internal organ. And for no current across the chest, the heart is saved.

Three lines are drawn through the grounded limbs. The distances between these lines are $\Delta \mathrm{r}$ and the voltage differences between them are $\Delta \mathrm{V}$. The line through the toes is at a higher potential $V_{1}$ than the line $\mathrm{V}_{2}$ through the knees. And the line through the knees is at a higher potential $\mathrm{V}_{2}$ than the line $\mathrm{V}_{3}$ through the palms, nose and forehead. Prostration picture was taken from (Ghazi and Ghazi, 1996) with permission.

If the person was standing instead of being in prostration, he is under an enhanced risk of getting the lightning struck. If he would just sit about two feet, he would not be able to lower his body like the prostration position and would be under the risk of lightning strike though smaller than when he is standing. 


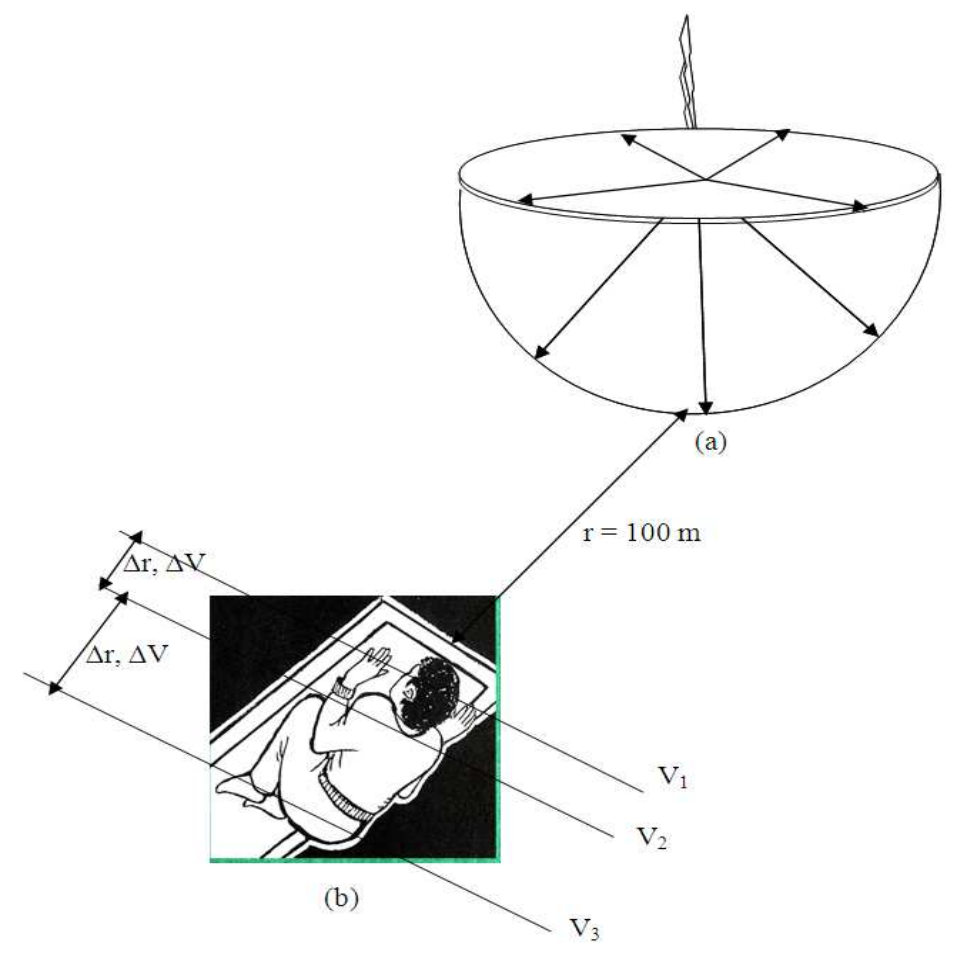

Fig. 3: (a) Lightning strike and current spread in a hemispherical volume, $r=100 \mathrm{~m}$ is the distance from the lightning-hit spot to the subject head, (b) Subject in prostration with lightning strike in the front.

Lightning strike in front of the person in prostration: If the lightning strike would be in the front of the person, the same situation of current flow as from the lightning strike behind the person would occur. Counting from the closest distance of lightning hit, the two palms, the nose tip and the forehead will be equidistant and so, will be equipotential. The two knees, about $40 \mathrm{~cm}$ away from the palms, will be equidistant from the lightning spot and so, will be equipotential. The two toes, about $40 \mathrm{~cm}$ away from the equipotential knees, will be equidistant and so, at equipotential. In this case $V_{1}>V_{2}>V_{3}$, shown in Fig. $3 a$ and $b$.

Lightning strike to the right of the person in prostration: If the lighting strike spot will be on the right side of the person (Fig. 4), one equipotential line $\mathrm{V}_{1}$ can be drawn through the right palm, the right knee and the right toe. The second equipotential line $V_{2}$ can be drawn through the left palm, the left knee and the left toe. This line will be at a lower potential than the first line. Little current flow will occur between the palm and nose-forehead on one side of the body and between nose-forehead and the palm on the other side of the body because of the shorter distance and hence smaller potential differences between them. Also, there will be a little current from one knee to the other knee and from one toe to the other toe for the same reason. No current will flow from the toe to knee to palm to forehead on one side or the other because of being at the same potential.

Lightning strike to the left of the person in prostration: If the lighting strike spot will be on the left side of the person (Fig. 5), the higher equipotential line $\mathrm{V}_{1}$ will pass through the left palm, the left knee and the left toe. The lower equipotential line $V_{2}$ passes through the right palm, the right knee and the right toe.

Lightning strike to the front-right of the person in prostration: In prostration, the palms and the knees form almost a square, the nose tip being the midpoint of the palms (Fig. 6). The right palm will be at the highest potential $\mathrm{V}_{1}$.

The higher equipotential line can be drawn through the left palm and the right knee $\mathrm{V}_{2}$. The lower equipotential line can be drawn through left knee and the right toe $V_{3}$. The lowest potential limb will be the right toe $\mathrm{V}_{4}$. There will be tolerable interlimb current as has been shown above. 
Phy. Intl. 3 (1): 9-21, 2012

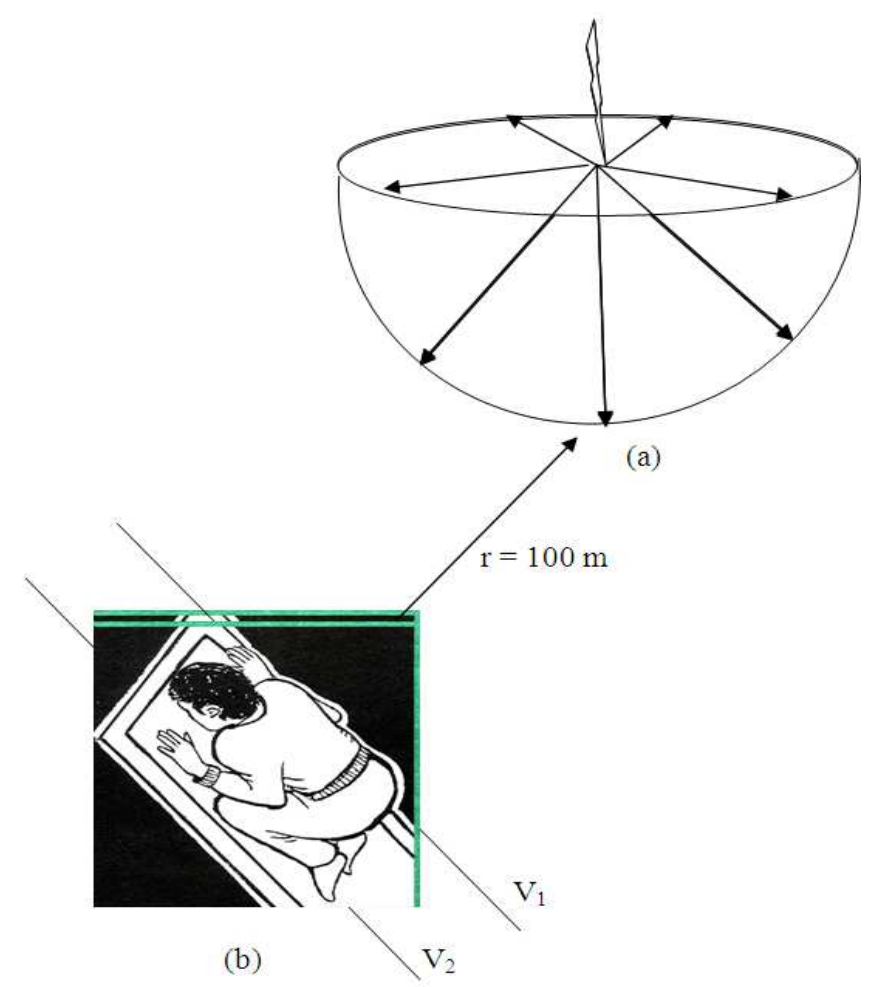

Fig. 4: (a) Lightning strike and current spread in a hemispherical volume, $r=100 \mathrm{~m}$ is the distance from the lightninghit spot to the subject's right side, (b) Subject in prostration with lightning-struck spot on the right side

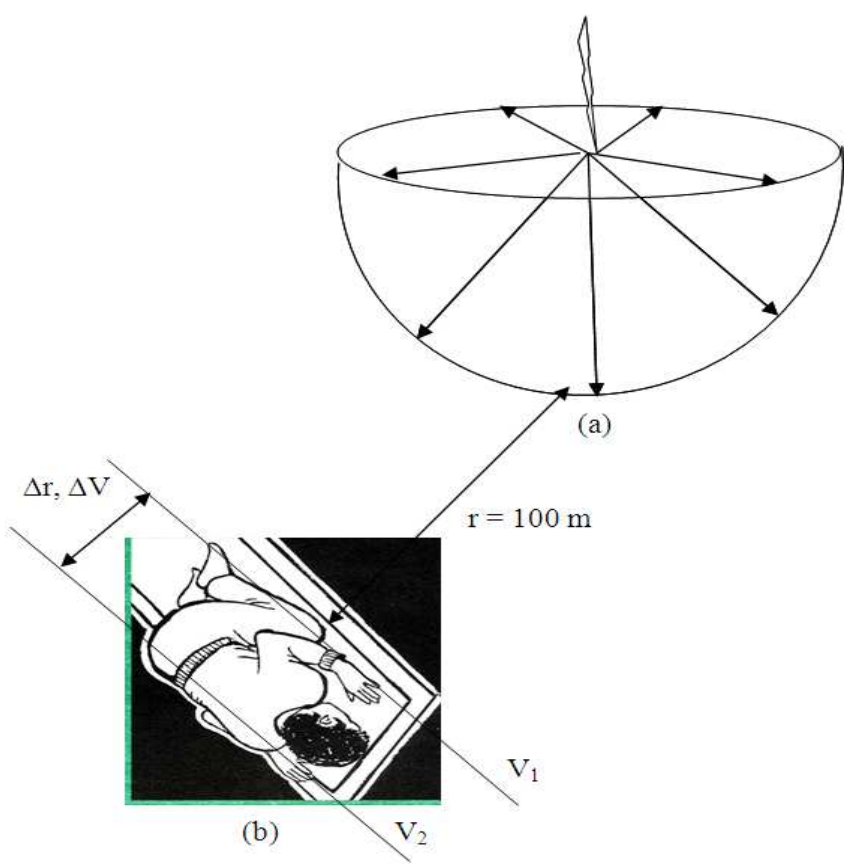

Fig. 5: (a) Lightning strike and current spread in a hemispherical volume, $r=100 \mathrm{~m}$ is the distance from the lightning-hit spot to the subject's left side, (b) Subject in prostration with the lightning strike to the left. 


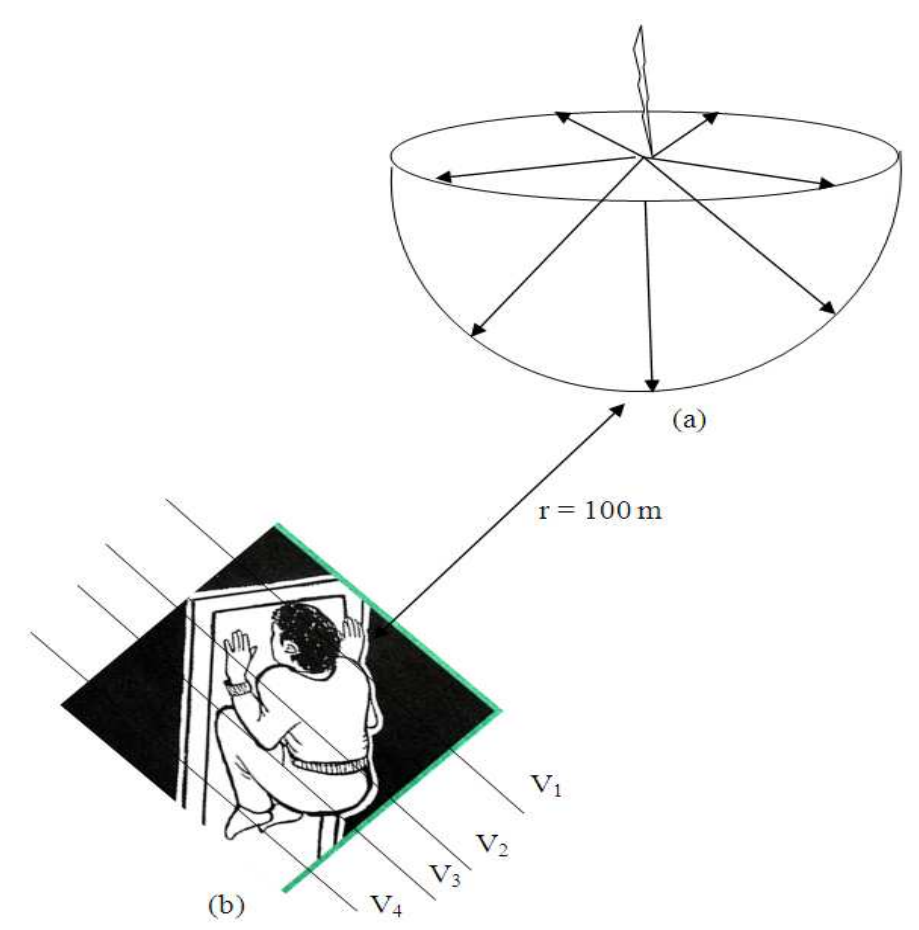

Fig. 6: (a) Lightning strike and current spread in a hemispherical volume, $r=100 \mathrm{~m}$ is the distance from the lightning-hit spot to the subject's front-right corner, (b) Subject in prostration with the lightning strike to the front-right

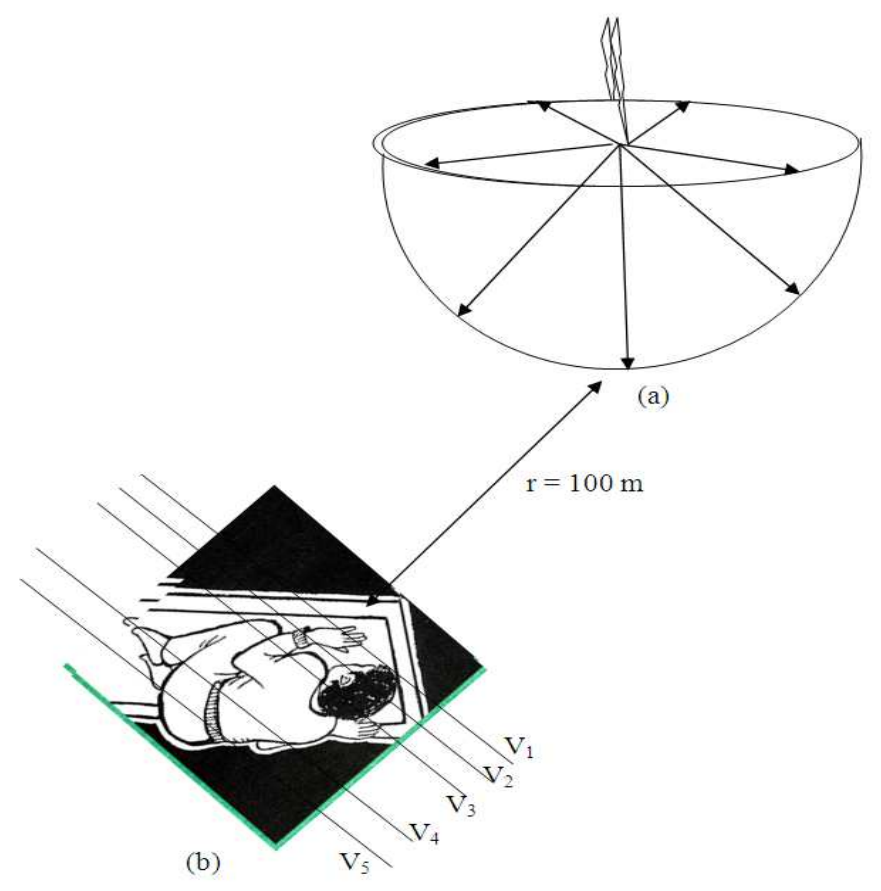

Fig. 7: (a) Lightning strike and current spread in a hemispherical volume, $r=100 \mathrm{~m}$ is the distance from the lightninghit spot to the subject's front-left corner, (b) Subject in prostration with the lightning strike to the front-left 


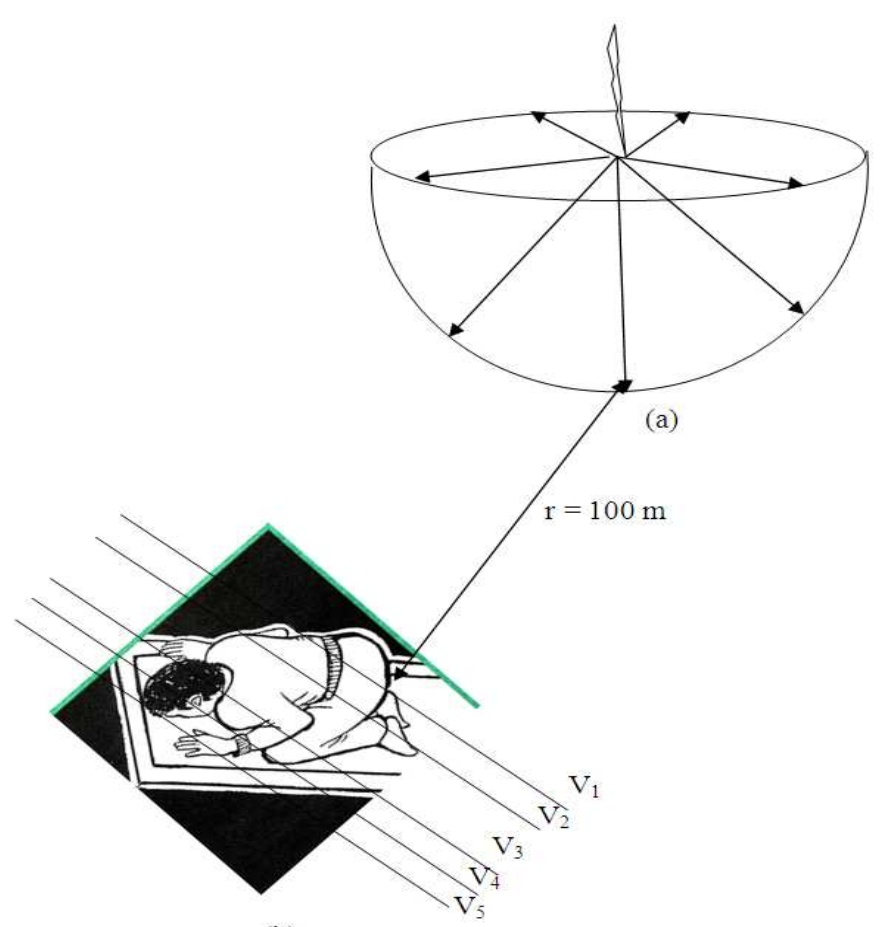

(b)

Fig. 8: (a) Lightning strike and current spread in a hemispherical volume, $\mathrm{r}=100 \mathrm{~m}$ is the distance from the lightning-hit spot to the subject's rear-right corner, (b) Subject in prostration with the lightning strike to the rearright.

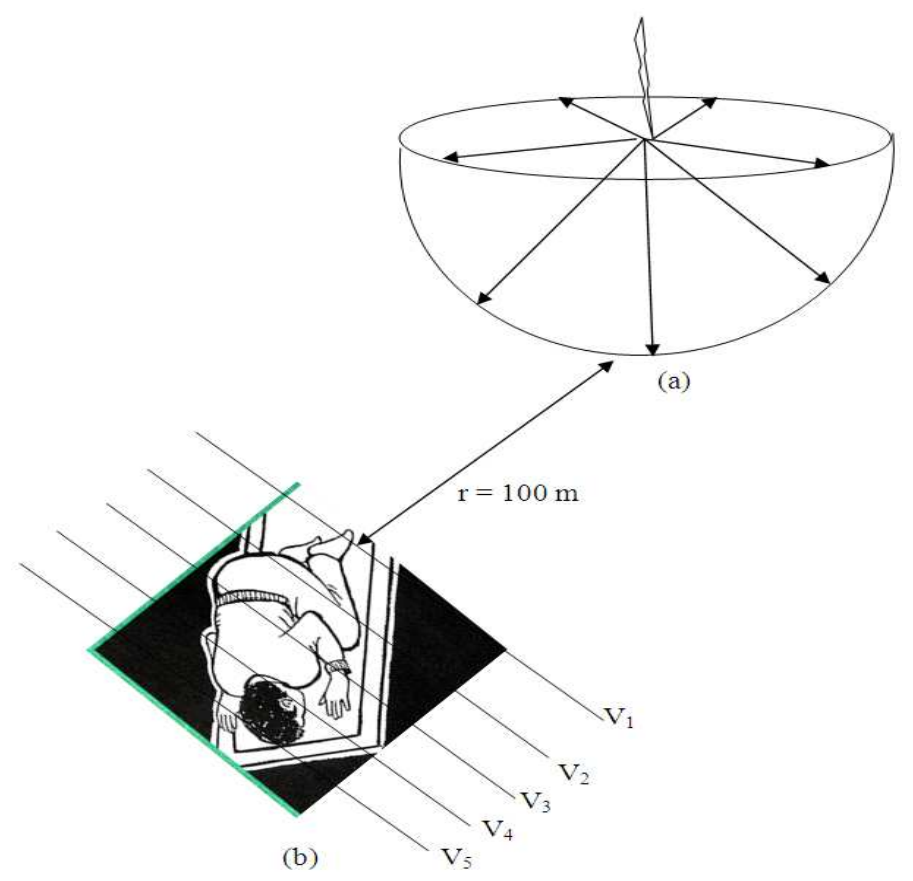

Fig. 9: (a) Lightning strike and current spread in a hemispherical volume, $r=100 \mathrm{~m}$ is the distance from the lightninghit spot to the subject's rear-left corner, (b) Subject in prostration with the lightning hit at the rear-left 
Lightning strike to the front-left of the person in prostration: In this situation (Fig. 7), the left palm will be at the highest potential $V_{1}$. The next lower potential line $\mathrm{V}_{2}$ is drawn for the nose tip-forehead. The next lower equipotential line can be drawn through the left knee and the right palm $\mathrm{V}_{3}$. The equipotential line through left toe and the right knee $\mathrm{V}_{4}<\mathrm{V}_{3}$. The limb at the lowest potential $V_{5}$ will be the right toe. The current flow will remain within tolerance.

Lightning strike to the rear-right of the person in prostration: The highest potential $\mathrm{V}_{1}$ will be with the right toe (Fig. 8). The higher equipotential line $V_{2}$ can be drawn through the right knee and the left toe. The lower equipotential line $\mathrm{V}_{3}$ can be drawn through the right palm and the left knee. The Nosetip - forehead will be at the next lower potential $\mathrm{V}_{4}$. The limb at the lowest potential $\mathrm{V}_{5}$ will be the left palm. The interlimb current flow will remain within the tolerance limit.

Lightning strike to the rear-left corner of the person in prostration: The left toe will be at the highest potential $\mathrm{V}_{1}$ and the right palm will be at the least potential $V_{5}$ (Fig. 9). The higher equipotential line $V_{2}$ can be drawn through the right toe and the left knee. The next high equipotential line $\mathrm{V}_{3}$ can be drawn through the right knee and the left palm. The nose tipforehead potential line is $\mathrm{V}_{4}$.

Other benefits of prostration: Prostration has other benefits, too. A thumb nail size part of our body is getting more than one cosmic ray particles every minute. Most abundant of them are muons that carry the same charge as an electron. Our movements outside our houses or cars determine the accumulation of charges from muons and other cosmic ray particles. This accumulated charge can be discharged by going to prostration because it grounds different parts of our body. An electronic technician better knows how these stray charges are bothersome to them.

\section{CONCLUSION}

Prostration offers the safest shelter for a person outside in the open field. It has the least chance of being an object of a direct hit by lightning, stream of positive charges, hit by side flashes, or ground current. And it is a comfortably stable position for subjects of all ages, sexes and body weights supported by seven grounded limbs in any terrain of the land. Other postures of our body have higher risks than prostration of being struck by lightning, an object of stream of positive charges, hit by side flashes, or ground current.
Those are not as comfortable stable as prostration for everyone in all terrains on land. Many fatalities can be avoided if people practice prostration and take shelter to it when they happen to be outside under lightning. Holding lightning drills before the arrival of the lightning season will be very helpful.

\section{ACKNOWLEDGEMENT}

The researcher is thankful to the source(s) for allowing him to use the illustration(s). The sources are referred in the text and in the reference section.

\section{REFERENCES}

Al-Abdulaziz, A.U., S.M. Bashi and A.A. Atthubaiti, 2006. Analysis of the over-voltages produced by lightning strokes in the power transmission system in the Southern Region of Saudi Arabia. Am. J. Applied Sci., 3: 1755-1759. DOI: 10.3844/ajassp. 2006.1755.1759

Albornoz, L., 2007. Safety tips: Lightning struck your car. Helium, Inc.

Coleman, P.F., 1993. An explanation for ball lightning? Weather, 48: 30-30.

Dell'Amore, C., 2010. A new lightning type found over volcano? National Geographic Society.

Demirkol, M.K., U.S. Inan, T.F. Bell, S.G. Kanekal and and D.C. Wilkinson, 1999. Ionospheric effects of relativistic electron enhancement events. Geophys. Res. Lett., 26: 3557-3560. DOI: 10.1029/1999GL010686

Djalel, D., H. Ali and C. Faycal, 2007. The return stroke of lightning current, source of electromagnetic fields (study, analysis and modeling). Am. J. Applied Sci., 4: 42-48. DOI: 10.3844/ajassp. 2007.42.48

Ghazi, A. and T.K. Ghazi, 1996. Our Faith and Worship. 1st Edn., IQRA International Educational Foundation, ISBN-10: 1563160609, pp: 58.

Giordano, N.J., 2009. College Physics: Reasoning and Relationships. 1st Edn., Cengage Learning, Belmont, Belmont, CA., ISBN-10: 0534424716, pp: 1082.

Halasa, G., I. Badran and H. El-Zayyat, 2007. Lightning over-voltages on Amman-Aqaba 400KV line. Am. J. Applied Sci., 4: 1075-1078. DOI 10.3844/ajassp. 2007.1075.1078

Halliday, D., R. Resnick and J. Walker, 2008. Fundamentals of Physics. 8th Edn., John Wilet and Sons, Hoboken, N.J., ISBN-10: 047177958X, pp: 266. 
Hyndman, D. and D. Hyndman, 2010. Natural Hazards and Disasters. 3rd Edn., Cengage Learning, Australia, ISBN-10: 0538737522, pp: 592.

Jewett, J.W. and R.A. Serway, 2007. Physics for Scientists and Engineers with Modern Physics. 7th Edn., Cengage Learning EMEA, Belmont, CA., ISBN-10: 0495112402, pp: 1392.

Khan, N., N. Mariun, I. Aris and J. Yeak, 2002. Lasertriggered lightning discharge. New J. Phys., 4: 6161. DOI: 10.1088/1367-2630/4/1/361.

Koopman, D.W. and T.D. Wilkerson, 1971. Channeling of an ionizing electrical streamer by a laser beam. J. Applied Phys., 42: 1883-1886. DOI: 10.1063/1.1660462

Meredith, S.L., S.K. Earles and N. Turner, 2010a. The horizontal electric field induced by a lightning return stroke. J. Math. Stat., 6: 210-216. DOI: 10.3844/jmssp. 2010.210.216

Meredith, S.L., S.K. Earles and N. Turner, 2010b. The magnetic field induced by a lightning Strike's indirect effect double exponential current waveform. J. Math. Stat., 6: 221-225. DOI: 10.3844/jmssp. 2010.221.225
NLSI, 2012. NLSI international lightning safety initiative. National Lightning Safety Institute.

Odeh, H.B., 2009. Usage of lightning arrester line to feed light electrical loads. Am. J. Applied Sci., 6: 13-23. DOI: 10.3844/ajassp. 2009.13.23

Petersen, D., M. Bailey, W.H. Beasley and J. Hallett, 2008. A brief review of the problem of lightning initiation and a hypothesis of initial lightning leader formation. J. Geophys. Res., 113: 1-14. DOI: 10.1029/2007JD009036

Rambo, P., J. Biegert, V. Kubecek, J. Schwarz and A. Bernstein et al., 1999. Laboratory tests of laserinduced lightning discharge. J. Optical Technol., 66: 194-198. DOI: 10.1364/JOT.66.000194

Saum, K.A. and D.W. Koopman, 1972. Discharges guided by laser-induced rarefaction channels. Phys. Fluids, 15: 2077-2079. DOI: 10.1063/1.1693833

Stolzenburg, M. and T.C. Marshall, 2008. Charge structure and dynamics in thunderstorms. Space Sci. Rev., 137: 355-372. DOI: 10.1007/s11214008-9338-z 